\title{
Bazı doğal mera alanlarının bitki örtüsü özellikleri, mera durumu ve sağlığının belirlenmesi
}

\author{
Seyithan Seydoşoğlua,*
}

\begin{abstract}
Özet: Bu araştırma, bazı doğal mera alanlarının bitki örtüsü özellikleri, mera durumu ve sağlığının belirlenmesi amacıyla 2015 yılında yürütülmüştür. Çalışma, Diyarbakır ili Çermik ilçesi sınırları içerisinde yer alan, ortalama 950 metre yükseklikte ve \%2-5 eğime sahip olan Artuk, Ağaçhan, Sarıbalta ve Örenkuru köyleri meralarında yapılmıştır. Araştırma sahasında, modifiye edilmiş tekerlekli lup (halka) metodu kullanılarak meranın bitki örtüsü özellikleri incelenmiștir. Çalışma alanında bitkiyle kaplı alan, botanik kompozisyon, takson sayıları, meralara ait bazı toprak özellikleri, mera durumu ve sağlığı gibi özellikler incelenmiştir. Meralarda 11 familyaya ait 36 takson tespit edilmiştir. En fazla taksona sahip familyalar 13 takson ile Fabaceae, 7 takson ile Asteraceae ve 6 takson ile Poaceae olarak belirlenmiştir. Bitki ile kaplı alan değeri \%64.25-82.25 arasında değişmiştir. Ayrıca botanik kompozisyondaki buğdaygiller, baklagiller ve diğer familyalara ait bitkiler sırasıyla \%30.35-50.68, \%16.73-32.09, 17.2352.92 arasında değişim göstermiş̧ir. Araştırmanın yapıldığı tüm mera alanları "zayıf mera" ve bir mera hariç diğerleri "sağlıklı mera" olarak tespit edilmiștir. Tüm mera alanlarında ıslah çalıșmasına ihtiyaç duyulduğu sonucuna varılmıștır. Ayrıca, bu meralarda sürdürülebilirliğin devam etmesi bakımından, otlatmanın planlanması, sonrasında başta gübreleme ve yabancı ot savaşımı olmak üzere bazı bakım ve ıslah işlemlerinin uygulamaya konulması ve uygulamaların da zaman zaman güncellenmesi gerekliliği göz önünde bulundurulmalıdır.

Anahtar kelimeler: Takson, Bitki ile kaplı alan, Familya, Tekerlekli lup
\end{abstract}

\section{Vegetation characteristics, rangeland status and health determination of some natural rangelands}

\begin{abstract}
This research was carried out in 2015 in order to determine vegetation characteristics, rangelands status and health of some natural rangelands. Studied rangelands are located in Diyarbakir province Cermik subprovince with average 950 meters altitude and 2-5\% slope in Artuk, Agachan, Sarıbalta and Orenkur villages. In the research area, the vegetation characteristics of the rangelands were examined by using modified wheeled loop method. In the study area, plant-covered area, botanical composition, taxa numbers, some soil properties of rangelands, rangeland status and health characteristics were examined. 36 taxa belonging to 11 families were determined in the rangelands. The families with the highest taxon were identified as Fabaceae with 13 taxa, Asteraceae with 7 taxa and Poaceae with 6 taxa. The share of the plant covered area ranged from 64.25-82.25\%. In addition, proportion of wheat, legumes, other family plants in the botanical composition were between $30.35-50.68 \%, 16.73-$ $32.09,17.23-52.92 \%$ respectively. All studied rangelands were "weak" and except one, all were classified as healthy. It was concluded that all studied rangelands are in need of improvement. In order to maintain sustainability of these rangelands, it is necessary to establish a grazing plan, implement a rehabilitation processes, particularly fertilization and weed control, and update the application plans periodically.
\end{abstract}

Keywords: Taxa, Plant covered area, Family, Wheeled loop

\section{Giriş}

Çayır ve meralar üretim potansiyelleri, kaliteleri ve karlılıkları nedeniyle hayvancılığın vazgeçilmez yem kaynaklarıdır. Ülkemiz arazilerinin \% 18.8'ini oluşturan çayır ve meralar, toplam olarak 14.6 milyon hektarlık geniş bir alanı kaplarlar. Çayır-meraların \% 85'i yarı kurak bölgelerde yer almaktadır (Gökkuş ve Koç, 2001; Altın vd., 2011). Yarı-kurak bir bölge içerisinde yer alan Diyarbakır ilinin yüzölçümü 15.355 .000 dekardır. Diyarbakır İli topraklarının 779.797 ha'ı tarım alanı, 230.092 ha'ı çayır ve mera, 265.365 ha'1 orman, 294.142 ha'1 da tarıma elverişsiz alandir (Anonim, 2017).
Çayır-meralar yenilebilen doğal kaynaklar olmakla birlikte, kullanım ilkelerine uyulmadığı takdirde kısa zamanda verimsiz ve çorak alanlar haline gelebilmektedir. Meraların büyük bir çoğunluğunun kurak ve yarı kurak iklim kuşağında yer alması ve yağışın düşüklüğü ile birlikte otlatma planlarının olmaması veya uyulmaması gibi etmenler meralarda bitki örtüsünün bozulmasının en önemli sebeplerdendir (Holechek vd., 2004). Bu durumda bitki örtüsünün zamanla kaybolması sonucu bu alanlar hem erozyona açık hale gelmekte hem de bu meraların verimi oldukça azalmaktadır. Nitekim ülkemizdeki meraların kapasitelerinin yaklaşık 2-3 katının üzerinde bir yoğunlukta otlatılmaları ile verimliliklerinin azalmasına yol açmıştır (Koç vd., 1994).

\footnotetext{
a Siirt Üniversitesi, Ziraat Fakültesi, Tarla Bitkileri Bölümü, Siirt, Türkiye Corresponding author (İletişim yazarı): seyithanseydosoglu @ siirt.edu.tr Received (Geliş tarihi): 21.11.2018, Accepted (Kabul tarihi): 16.12.2018
}

Citation (Atıf): Seydoşoğlu, S., 2018. Bazı doğal mera alanlarının bitki örtüsü özellikleri, mera durumu ve sağlığının belirlenmesi. Turkish Journal of Forestry, 19(4): 368-373. DOI: $10.18182 /$ tif. 486291 
$\mathrm{Bu}$ araştırma, bazı doğal mera alanlarının bitki örtüsü özellikleri, mera durumu ve sağlığının belirlenmesi amacıyla yürütülmüştür.

\section{Materyal ve yöntem}

Araştırma; Diyarbakır ili Çermik ilçesine bağlı Artuk, Ağaçhan, Sarıbalta ve Örenkuyu köylerine tahsisli, 4 farklı doğal merada 15 Mayıs - 15 Haziran 2015 tarihleri arasında yürütülmüştür (Şekil 1). İncelenen meralar; kuraklık indeksi, bakı ve rakım bakımından nispeten aynı homojen alanda yer almıştır (Avağ vd., 2012).

Çalışmanın yürütüldüğü mera alanlarına en yakın meteoroloji istasyonu olan Diyarbakır Meteoroloji Müdürlüğü verilerine göre; Diyarbakır'da 2015 yılı toplam yağışı $(477.2 \mathrm{~mm})$ uzun yıllar ortalaması yıllık yağış toplamına $(484.9 \mathrm{~mm})$ yakın gerçekleşirken, 2015 yılı ortalama sicaklığı $\left(18.5^{\circ} \mathrm{C}\right)$ uzun yillar sicaklık ortalaması $\left(15.8{ }^{\circ} \mathrm{C}\right)$ 'nın üzerinde gerçekleşmiştir. Uzun yıllar ortalaması ve 2015 iklim verilerine göre; en soğuk ay Şubat, en sicak ay ise Ağustos ayı olmuştur (Anonim, 2018).

Mera alanlarına ait toprak analiz sonuçları ve değerlendirmeleri (Çizelge 1) incelendiğinde; meralardaki topraklarının killi-tınlı sınıfına girdiği belirlenmiştir. Topraklardaki kireç miktarının \%0.79-1.08 ile kireçsiz, organik madde miktarının \%0.95-1.22 ile fakir ve tüm mera topraklarının tuzsuz olduğu tespit edilmiştir. Çalışma sahasındaki topraklarının su ile doymuş topraktaki $\mathrm{pH}$ değerleri 7.32-7.48 ile Artuk ve Örenkuyu meralarda bazik iken, Ağaçhan ve Sarıbalta köylerinin su ile doymuş topraktaki $\mathrm{pH}$ değerleri 6.69-6.81 ile hafif asitli olduğu belirlenmiştir. Mera topraklarının makro besin elementlerinden potasyum miktarı tüm köylerde yeterli bulunmuştur. Mera alanlarındaki fosfor miktarı Ağaçhan ve Örenkuyu meralarında yeterli iken, Artuk ve Sarıbalta köyleri meralarının ise yetersiz olduğu saptanmıştır (Çizelge 1).

Araştırmada meralardaki bitki örtüsü özelliklerinin ölçümleri modifiye edilmiş tekerlekli lup (halka) metodu kullanılarak meralardaki hâkim bitkilerin çiçeklenme evresinde Koç ve Çakal (2004)'ın ifade ettiği şekilde belirlenmiştir (Şekil 2). Lup ölçümleri; her bir merada vejetasyon ve toprak açısından oldukça homojen olan bir blokta ve merkez olarak kabul edilen bir noktadan itibaren 4 ana yöneye doğru uzanan 20 m'lik 4 hat boyunca yapılmıştır. Her 20 m'lik hat üzerinde toplam 100 ve her blokta 400 olmak üzere lup ölçümü yapılmıştır. İncelenen meralarla ilgili olarak; bitki ile kaplı alan ve alana göre botanik kompozisyon Gökkuş vd. (2000) tarafindan açıklanan yöntemlere göre yapılmıştır. Mera alanlarındaki bitki teşhisleri için; Türkiye'nin Çayır ve Mera Bitkileri kitabından yararlanılmıştır. Arazide teşhisi yapılamayan bitki türleri usulüne uygun olarak toplanmış ve herbaryumda teşhisleri yapılmıştır. Okuma neticesinde tespit edilen bitki türleri azalıcılar, çoğalıcılar ve istilacılar olmak üzere 3 sınıfa ayrılmışlardır. Tespit edilen bitkilerden azalıcıların tamamı ve çoğalıcıların ise \%20'si dikkate alınarak çalışılan meralarda mera durumu sınıflaması yapılmıştır (Altın vd., 2011). Meraların durum ve sağlık sınıflamaları, Koç vd. (2003)'nin ifade edilen kriterlere göre yapılmıştır (Çizelge 2).

Çizelge 1. Mera alanlarına ait toprakların bazı özellikleri $(0-20 \mathrm{~cm})^{*}$

\begin{tabular}{|c|c|c|c|}
\hline \multirow{8}{*}{ Artuk } & Analiz adı & Sonuçlar & Değerlendirme \\
\hline & Bünye sinıfi & 56.1 & Killi-tınlı \\
\hline & $\mathrm{EC}\left(\mathrm{ds} \mathrm{m^{-1 } )}\right.$ & 0.717 & Tuzsuz \\
\hline & Su ile doymuş toprakta $\mathrm{pH}$ & 7.48 & Bazik \\
\hline & Kireç $(\%)$ & 1.01 & Kireçsiz \\
\hline & Organik madde $(\%)$ & 0.95 & Fakir \\
\hline & Bitkiye yarayışlı fosfor (kg/da) & 3.15 & Yetersiz \\
\hline & Bitkiye yarayışlı potasyum $(\mathrm{kg} / \mathrm{da})$ & 65.72 & Yeterli \\
\hline \multirow{7}{*}{ Ağaçhan } & Bünye sınıfi & 54.4 & Killi-tınlı \\
\hline & $\mathrm{EC}\left(\mathrm{ds} \mathrm{m}^{-1}\right)$ & 0.587 & Tuzsuz \\
\hline & Su ile doymuş toprakta $\mathrm{pH}$ & 6.69 & Hafif asitli \\
\hline & Kireç $(\%)$ & 0.79 & Kireçsiz \\
\hline & Organik madde $(\%)$ & 1.15 & Fakir \\
\hline & Bitkiye yarayışlı fosfor (kg/da) & 7.22 & Yeterli \\
\hline & Bitkiye yarayışlı potasyum $(\mathrm{kg} / \mathrm{da})$ & 28.13 & Yeterli \\
\hline \multirow{7}{*}{ Sarıbalta } & Bünye sınıfi & 57.6 & Killi-tınlı \\
\hline & $\mathrm{EC}\left(\mathrm{ds} \mathrm{m}^{-1}\right)$ & 0.797 & Tuzsuz \\
\hline & Su ile doymuş toprakta $\mathrm{pH}$ & 6.81 & Hafif asitli \\
\hline & Kireç $(\%)$ & 1.08 & Kireçsiz \\
\hline & Organik madde $(\%)$ & 1.05 & Fakir \\
\hline & Bitkiye yarayışlı fosfor $(\mathrm{kg} / \mathrm{da})$ & 5.42 & Yetersiz \\
\hline & Bitkiye yarayışlı potasyum $(\mathrm{kg} / \mathrm{da})$ & 26.21 & Yeterli \\
\hline \multirow{7}{*}{ Örenkuyu } & Bünye sinifi & 53.2 & Killi-tınlı \\
\hline & $\mathrm{EC}\left(\mathrm{ds} \mathrm{m^{-1 } )}\right.$ & 0.627 & Tuzsuz \\
\hline & Su ile doymuş toprakta $\mathrm{pH}$ & 7.32 & Bazik \\
\hline & Kireç $(\%)$ & 0.79 & Kireçsiz \\
\hline & Organik madde $(\%)$ & 1.22 & Fakir \\
\hline & Bitkiye yarayışlı fosfor (kg/da) & 7.69 & Yeterli \\
\hline & Bitkiye yarayışlı potasyum $(\mathrm{kg} / \mathrm{da})$ & 24.33 & Yeterli \\
\hline
\end{tabular}

${ }^{*}$ Toprak, Gübre ve Su Kaynakları Merkez Araştırma Enstitüsü Müdürlüğü tarafından yapılmıştır. 
Çizelge 2. Mera durum sınıfı ve sağlığı değerlendirmesi

\begin{tabular}{cccc}
\hline \multicolumn{2}{c}{ Mera durum sınıflaması } & \multicolumn{2}{c}{ Mera sağlığı } \\
\hline $\begin{array}{c}\text { Hesaba katılan } \\
\text { türlerin }(\%)\end{array}$ & $\begin{array}{c}\text { Durum } \\
\text { sinıfi }\end{array}$ & $\begin{array}{c}\text { Bitki ile kaplı } \\
\text { alan }(\%)^{*}\end{array}$ & Sağlık sınıfı \\
\hline $76-100$ & Çok İyi & $>70$ & Sağlıklı \\
$51-75$ & İyi & $55-70$ & Riskli \\
$26-50$ & Orta & 55 & Sorunlu \\
$0-25$ & Zayıf & & \\
\hline
\end{tabular}

${ }^{*}$ Modifiye edilmiş tekerlekli halka yöntemi verilerine göre uyarlanmıştır.

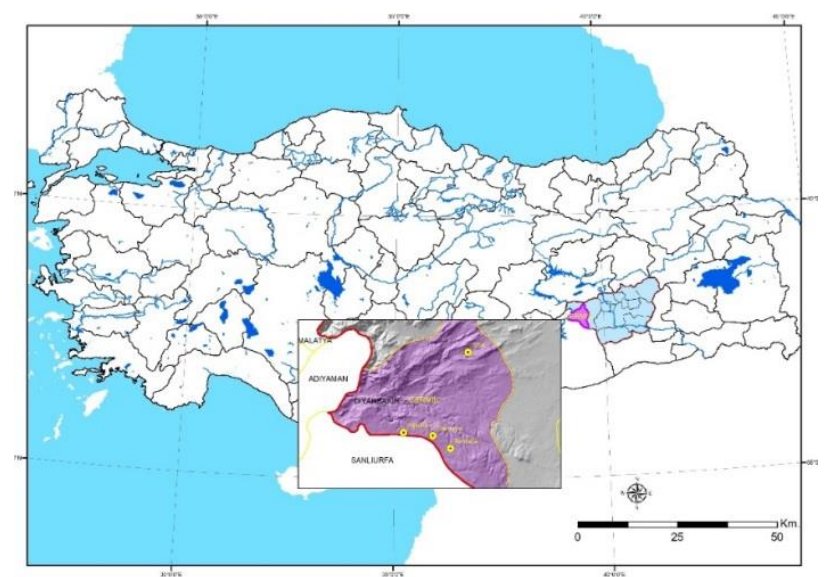

Şekil 1. Mera alanlarına ait duraklar

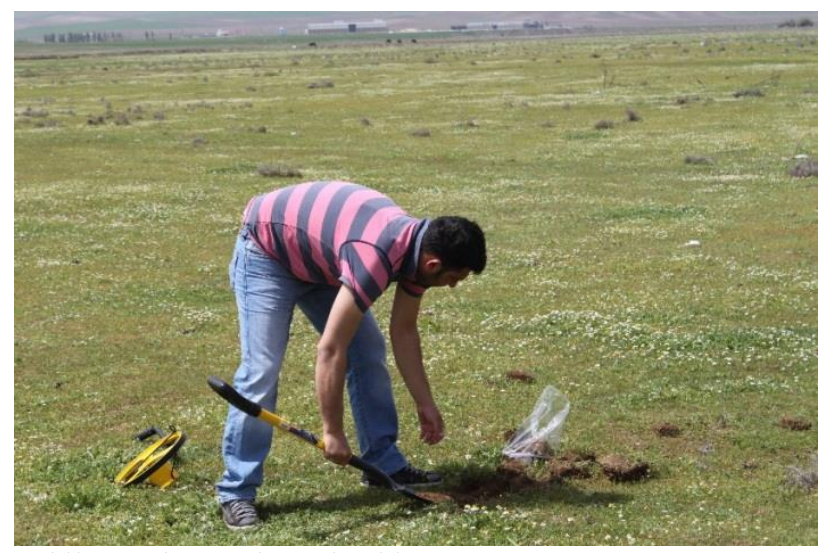

Şekil 2. Çalışma alanından bir görüntü

Takson sayıları

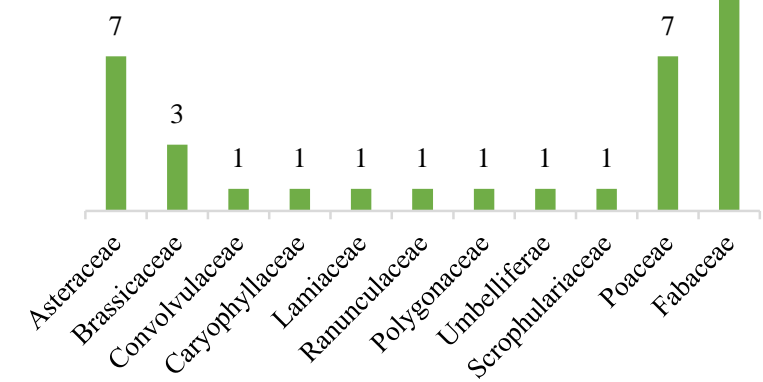

Şekil 3. Takson sayılarına göre meralarda bulunan familyalar

\section{Bulgular ve tartışma}

Mera alanlarında bulunan bitkilere bakıldığında (Çizelge 3); 11 familyadan 24 cins ve 36 takson tespit edilmiştir. Bu 36 taksonun 6'sını buğdaygiller, 13'unu baklagiller, 17'sini ise diğer familyalara ait bitkiler oluşturmuştur. Meraların bitki örtüsünde en çok 13 takson ile Fabaceae familyasından bitkilere rastlanmıştır (Şekil 3). Mera alanlarında toplam 26 adet tek yıllık, 9 adet çok yıllık ve 1 adet iki yıllık bitki tespit edilmiştir (Çizelge 3).

Gobelle ve Gure (2018) Borana meralarında yaptıkları çalışmada, 10 adet buğdaygil, 8 adet baklagil ve 35 adet diğer familya bitkileri olmak üzere toplam 53 türe rastlandıklarını bildirmişlerdir. Yine Uzun vd. (2016) Bartın ili meralarında yürüttükleri çalışmada, 18 adet buğdaygil, 31 tane baklagil ve 69 tane de diğer familya bitkileri belirlemişlerdir.

Mera alanlarında 2015 yılının 15 Mayıs -15 Haziran aylarında vejetasyon ölçümleri yapılmış olup, bitkiyle kaplı alan değerleri Çizelge 4'te belirtilmiştir. Bitkiyle kaplı alan değeri en yüksek \%82.25 ile Artuk köyü merasında tespit edilirken, en düşük \%64.25 ile Örenkuyu köyü merasında elde edilmiştir. Bitki ile kaplı alanda; buğdaygillerin oranı en yüksek Ağaçhan köyü merasından elde edilirken, en düşük \%19.50 ile Örenkuyu köyü merasında saptanmıştır. Baklagillerin oranı \%10.75-23.75 arasında değişim göstermiştir. Diğer familya bitkileri oranına bakıldığında ise; Artuk ve Örenkuyu köyleri meralarının değerleri birbirine yakın ve diğer mera alanlarından yüksek bulunmuştur (Çizelge 4).

Tüm mera alanlarının bitki ile kaplı alan ve alana göre buğdaygil, baklagil, diğer familya bitkilerinin bitki ile kaplı alan değerleri birbirinden farklıdır. $\mathrm{Bu}$ durum, mera alanlarının toprak özellikleri, köylere ait hayvan varlıklarının, hayvan cinslerinin, otlatma sistemlerinin ve mera alanlarının birbirinden farklı olmasından kaynaklanmaktadır.

Bitkiyle kaplı alan ve alana göre botanik kompozisyon değerleri ile ilgili yapılan çeşitli çalışmalar mevcuttur. Örneğin, Eskişehir ili Karaören köyü merasında, bitki ile kaplı alan değeri \%51.2, bitki ile kaplı alanda ortalama buğdaygillerin değeri \%22.67, baklagillerin değeri \%11.55, diğer familya bitkileri değeri ise \%16.98 olarak tespit edilmiştir (Babalık ve Ercan, 2018). Isparta ili Çatoluk köyü merasında, bitki ile kaplı alan değeri \%42.6, bitki ile kaplı alanda ortalama buğdaygillerin değeri $\% 22.4$, baklagillerin değeri \%7.7, diğer familya bitkileri değeri ise \%12.5 olarak belirlenmiştir (Dursun ve Babalık, 2018). Mardin ilinde yapılan bir çalışmada, ortalama bitki ile kaplı alan değeri \%71.35 olarak tespit edilmiştir (Seydoşoğlu vd., 2018). İran bölgesinde yapılan çalışmada da, ortalama bitki ile kaplı alan değeri \%44.1 olarak belirlenmiştir (Azarnivand vd., 2011). Elde edilen bulgular ile yukarıda belirtilen literatürdeki sonuçlar arasında benzerlik ve farklılıklar mevcuttur. Bu farklılıkların nedeni olarak, yem bitkilerinin ekilişi, vejetasyon ölçme yöntemi (şerit, lup), vejetasyon dönemi (güz-yaz) ve en önemlisi de farklı ekolojik koşullar (nem, sıcaklık, yağış, vb.) gösterilebilir.

Mera alanlarındaki bitki türleri; buğdaygiller, baklagiller ve diğer familya bitkiler olmak üzere üç grupta toplanarak incelenmiş ve bitkiyle kaplı alana göre botanik kompozisyondaki oranları belirlenmiştir (Çizelge 5). Bitki ile kaplı alana göre botanik kompozisyon değerleri 
incelendiğinde; en yüksek buğdaygil değeri \%50.68 ile Ağaçhan köyü merasında, en düşük buğdaygil değeri ise \%30.35 ile Örenkuyu köyü merasında tespit edilmiştir. Aynı şekilde, en yüksek baklagil değeri Ağaçhan köyü merasında tespit edilirken, en düşük baklagil değeri ise Örenkuyu köyü merasında elde edilmiştir. Bitkiyle kaplı alana göre botanik kompozisyondaki diğer familya değerleri \%17.23-52.92 arasında değişmiștir (Çizelge 5). Bitki ile kaplı alandaki miktara göre botanik kompozisyon (buğdaygil, baklagil ve diğer familya) değerleri tüm köylerde farklı sonuçlar elde edilmiştir. Bu farklılıklar, köylere ait hayvan sayısı, cinsi ve toprak özelliklerinden kaynaklanmaktadır.
Babalık ve Ercan (2018)'ın Eskişehir ili Karaören köyü merasındaki çalışmalarında, botanik kompozisyonun yaklaşık \%44'ünü buğdaygiller, \%23'ünü baklagiller ve \%33'ünü diğer familya bitkilerden oluştuğunu bildirmişlerdir. Babalık ve Fakir (2017) Isparta ili Davraz Dağı Kozağacı Yaylası Kocapınar merasında, bitki örtüsünün botanik kompozisyonunda, toplam buğdaygil oranı otlatılan alanda \%60.9, korunan alanda $\% 58.7$, baklagil oranı aynı sırayla \%14.4 ve \%18.0, diğer familyalara giren tür oranları ise $\% 24.7$ ve $\% 23.3$ olarak tespit etmişlerdir.

Çizelge 3. Mera alanlarında bulunan türler

\begin{tabular}{|c|c|c|c|c|c|c|c|}
\hline Familya & Tür & Ömrü & Etkisi & Familya & Tür & Ömrü & Etkisi \\
\hline Brassicaceae & Alyssum strigosum & Tek Yıllık & $\dot{\mathrm{I}}$ & Poaceae & Bromus tectorum & Tek Yıllık & $\dot{\mathrm{I}}$ \\
\hline Brassicaceae & Capsella bursa-pastoris & Tek Yıllık & $\dot{\mathrm{I}}$ & Poaceae & Cynodon dactylon & Çok Yıllık & Ç \\
\hline Brassicaceae & Sinapis arvensis & Tek Yillık & $\dot{\mathrm{I}}$ & Fabaceae & Trifolium arvense & Tek Yillık & $\dot{\mathrm{I}}$ \\
\hline Scrophulariaceae & Verbascum geminiflorum & İki Yıllık & $\dot{\mathrm{I}}$ & Poaceae & Hordeum murinum & Tek Y1llık & $\dot{I}$ \\
\hline Umbelliferae & Torilis leptocarpa & Çok Yillık & $\dot{\mathrm{I}}$ & Poaceae & Cornucopiae cucullatum & Tek Yıllık & $\dot{\mathrm{I}}$ \\
\hline Convolvulaceae & Convolvulus betonicifolius & Çok Yıllık & $\dot{\mathrm{I}}$ & Poaceae & Poa bulbosa & Çok Yıllık & Ç \\
\hline Caryophyllaceae & Vaccaria pyramidata & Tek Yillık & $\dot{\mathrm{I}}$ & Poaceae & Bromus rubens & Tek Yillık & $\dot{\mathrm{I}}$ \\
\hline Lamiaceae & Ziziphora capitata & Tek Yıllık & $\dot{\mathrm{I}}$ & Fabaceae & Trifolium fragiferum & Çok Yıllık & A \\
\hline Ranunculaceae & Ranunculus arvensis & Tek Yillık & $\dot{\mathrm{I}}$ & Fabaceae & Trifolium resupinatum & Tek Yillık & $\dot{\mathrm{I}}$ \\
\hline Polygonaceae & Rumex patientia & Çok Yıllık & $\dot{\mathrm{I}}$ & Fabaceae & Trifolium hirtum & Tek Y1llık & $\dot{I}$ \\
\hline Asteraceae & Centaurea iberica & Tek Yillık & $\dot{\mathrm{I}}$ & Fabaceae & Trifolium pilulare & Tek Yillık & $\dot{\mathrm{I}}$ \\
\hline Asteraceae & Gundelia tournefortii & Çok Yillık & $\dot{\mathrm{I}}$ & Fabaceae & Trifolium scabrum & Tek Yıllık & $\dot{I}$ \\
\hline Asteraceae & Anthemis wiedemanniana & Tek Yillık & $\dot{\mathrm{I}}$ & Fabaceae & Trifolium globosum & Tek Y1llık & $\dot{I}$ \\
\hline Asteraceae & Crepis foetida & Tek Yillık & $\dot{\mathrm{I}}$ & Fabaceae & Medicago rigidula & Tek Yillık & $\dot{\mathrm{I}}$ \\
\hline Asteraceae & Tripleurospermum parviflorum & Çok Yillık & $\dot{\mathrm{I}}$ & Fabaceae & Trifolium nigrescens & Tek Yillık & $\dot{\mathrm{I}}$ \\
\hline Asteraceae & Carduus pycnocephalus & Tek Y1llık & $\dot{\mathrm{I}}$ & Fabaceae & Trifolium bullatum & Tek Y1llık & $\dot{I}$ \\
\hline Asteraceae & Anthemis cotula & Tek Yillık & $\dot{\mathrm{I}}$ & Fabaceae & Trifolium pauciflorum & Tek Y1llık & $\dot{\mathrm{I}}$ \\
\hline Fabaceae & Astragalus plumosus & Çok Yillık & $\dot{\mathrm{I}}$ & Fabaceae & Trifolium campestre & Tek Yillık & $\dot{\mathrm{I}}$ \\
\hline
\end{tabular}

İ: istilacı A: azalıcı Ç: çoğalıcı

Çizelge 4. Mera alanlarına ait bitki ile kaplı alan değerleri

\begin{tabular}{|c|c|c|c|}
\hline \multirow{6}{*}{ Artuk köyü } & Familyalar & Bitki ile kaplı alan (\%) & Toplam (\%) \\
\hline & Buğdaygiller & 31.75 & \multirow{3}{*}{82.25} \\
\hline & Baklagiller & 15.50 & \\
\hline & Diğer familyalar & 35.00 & \\
\hline & Boş alan & 17.75 & 17.75 \\
\hline & Toplam (\%) & 100.00 & 100.00 \\
\hline \multirow{5}{*}{ Ağaçhan köyü } & Buğdaygiller & 37.50 & \multirow{3}{*}{74.00} \\
\hline & Baklagiller & 23.75 & \\
\hline & Diğer familyalar & 12.75 & \\
\hline & Boș alan & 26.00 & 26.00 \\
\hline & Toplam & 100.00 & 100.00 \\
\hline \multirow{5}{*}{ Sarıbalta köyü } & Buğdaygiller & 32.50 & \multirow{3}{*}{72.00} \\
\hline & Baklagiller & 17.50 & \\
\hline & Diğer familyalar & 22.00 & \\
\hline & Boş alan & 28.00 & 28.00 \\
\hline & Toplam & 100.00 & 100.00 \\
\hline \multirow{5}{*}{ Örenkuyu köyü } & Buğdaygiller & 19.50 & \multirow{3}{*}{64.25} \\
\hline & Baklagiller & 10.75 & \\
\hline & Diğer familyalar & 34.00 & \\
\hline & Boş alan & 35.75 & 35.75 \\
\hline & Toplam & 100.00 & 100.00 \\
\hline
\end{tabular}

Çizelge 5. Bitki ile kaplı alan miktarına göre botanik kompozisyon

\begin{tabular}{|c|c|c|c|c|}
\hline \multicolumn{5}{|c|}{ Botanik kompozisyon (\%) } \\
\hline Familyalar & Artuk köyü & Ağaçhan köyü & Sarıbalta köyü & Örenkuyu köyü \\
\hline Buğdaygiller & 38.61 & 50.68 & 45.14 & 30.35 \\
\hline Baklagiller & 18.84 & 32.09 & 24.30 & 16.73 \\
\hline Diğer familyalar & 42.55 & 17.23 & 30.56 & 52.92 \\
\hline Toplam & 100.00 & 100.00 & 100.00 & 100.00 \\
\hline
\end{tabular}


Dursun ve Babalık (2018) Isparta ili Çatoluk köyü merasında, alanın botanik kompozisyonunu buğdaygiller $\% 52.44$, baklagiller $\% 18.04$ ve diğer familya bitkileri $\% 29.52$ olarak tespit etmişlerdir. Karakuş ve Deveci (2018)'nin Anadolu'nun Alp dağlarında yaptığı çalışmada, mera alanının botanik kompozisyondaki buğdaygillerin değeri \%31.61, baklagillerin değeri \%18.65, diğer familya bitkileri değeri \%49.74 olarak belirlenmiştir. Elde edilen veriler ile yukarıdaki araştırıcıların bulguları arasında benzerlik ve farklılıklar bulunmuştur. $\mathrm{Bu}$ farklılıkların oluşmasında, iklim özellikleri ve farklı topografik faktörler başta olmak üzere aşırı otlatmanın da etkili olduğu söylenebilir.

Bitki ile kaplı alana göre mera sağlığ sonuçları incelendiğinde (Çizelge 6); Artuk, Ağaçhan ve Sarıbalta köylerine ait meralar "sağlıklı mera" iken, Örenkuyu köyü merası "riskli mera" olarak bulunmuştur. Mera durumu bakımından incelendiğinde ise, tüm meralar "zayıf mera" sınıfına dahil olmuştur. Çınar vd. (2014)'nin Hatay ilinde, Seydoşoğlu vd. (2018)'nin Mardin ilinde yaptıkları çalışmalarda da benzer sonuçlar elde edilmiştir.

\section{Sonuç ve öneriler}

Türkiye'nin Güneydoğu Bölgesinde yer alan Diyarbakır ili Çermik ilçesi sınırları içerisinde yer alan Artuk, Ağaçhan, Sarıbalta ve Örenkuyu köyleri doğal meralarında yapılan araştırmada, genel toprak özellikleriyle birlikte, vejetasyon, bitkiyle kaplı alan, botanik kompozisyon, mera durumu ve mera sağlığı gibi özellikler incelenmiş ve bunlarla ilgili aşağıdaki sonuçlara ulaşılmıştır.

Mera alanlarındaki toprak yapısının bünyeleri killi-tınlı, tuzsuz, 2 mera alanı bazik iken diğer 2 meranı hafif asidik, kireçsiz, organik madde bakımından yetersiz, bitkiye yarayışlı fosfor miktarı 2 mera alanında yeterli iken diğer 2 mera alanında yetersiz, bitkiye yarayışı tüm mera alanlarında yeterli bulunmuştur. Mera alanlarda bulunan bitki türlerinden 9 tanesi çok yıllık, 1 tanesi iki yıllık, 26 tanesi de tek yıllık bitki olarak tespit edilmiştir. Mera alanlarının ortalama bitki ile kaplı alan değeri \% 73.13 , bitki ile kaplı alandaki ortalama buğdaygillerin, baklagillerin, diğer familya bitkilerinin oranları sırasıyla $\% 30.31, \% 16.88, \% 25.94$ olarak tespit edilmiştir. Araştırma sahasının botanik kompozisyondaki buğdaygillerin ortalama değeri \%41.20, baklagillerin \%22.99, diğer familya bitkileri ise \%35.81 olarak elde edilmiştir. Mera durumu bakımından tüm meraların zayıf mera, mera sağlığı yönünden ise 3 mera alanı sağlıklı mera diğeri ise riskli mera olarak bulunmuştur.

Tüm mera alanlarında ıslah çalışmasına ihtiyaç duyulduğu sonucuna varılmıştır. Ancak bu meralarda sürdürülebilirliğin devam etmesi bakımından, ilk olarak otlatmanın planlaması, sonrasında başta gübreleme ve yabancı ot savaşımı olmak üzere bazı bakım ve ıslah işlemlerinin uygulamaya konulması ve ayrıca uygulamaların da zaman zaman yenilenmesi gerekliliği göz önünde bulundurulmalidır.

Çizelge 6. Mera sağlı̆̆ 1 ve durumu

\begin{tabular}{lccc}
\hline Köyler & Bitki ile kaplı alan (\%) & Mera sağlığı & Mera durumu \\
\hline Artuk & 82.25 & Sağglıkl1 & Zayıf \\
Ağaçhan & 74.00 & Sağlıklı & Zayıf \\
Sarbalta & 72.00 & Sağlıklı & Zayıf \\
Örenkuyu & 64.25 & Riskli & Zayıf \\
\hline
\end{tabular}

\section{Açıklama}

$\mathrm{Bu}$ çalışma Bitkisel Üretim Genel Müdürlüğü (BÜGEM) tarafından desteklenen "Mera Varlığı ve Mera Durum Sinıflarının Belirlenmesi” adlı proje kapsamında yapılmıştır.

\section{Kaynaklar}

Altın, M., Gökkuş, A., Koç, A., 2011. Çayır ve mera yönetimi (Genel ilkeler). T.C. Tarım ve Köyişleri Bakanlığı Tarımsal Üretim ve Geliştirme Genel Müdürlüğü, Ankara, Cilt (1): 64-65.

Anonim, 2017. Diyarbakır ili 2017 y1lı çevre durum raporu. http://webdosya.csb.gov.tr/db/ced/icerikler/d-yarbak-r_cdr2017-20180711164325.pdf. Erişim: 20.11.2018.

Anonim, 2018. Meteoroloji Genel Müdürlügü Diyarbakır İli İklim Verileri. http://www.diyarbakir.mgm.gov.tr, Erişim: 15.11.2018.

Avağ, A., Mermer, A., Yıldız, H., Ünal, E., Urla, Ö., Aydoğdu, M., Dedeoğlu, F., Aydoğmuş, O., Torunlar, H., Tuğaç, M.G., Ünal, S., Mutlu, Z., Özaydın, K.A., Özgöz, M.M., Aksakal, E., Kara, A., Uzun, M., Çakal, Ş., Yıldırım, T., Aksoyak, Ş., Tezel, M., Aygün, C., Kara, İ., Erdoğdu, İ., Sever, L., Atalay, A., Yavuz, T., Avcı, M., Çınar, S., İnal, İ., Yücel, C., Cebel, H., Keçeci, M., Başkan, O., Depel, G., Palta, Ç., Çarkacı, A., Karadavut, U., Şimşek, U., Sürmen, M., Odabaşı, G., Gül, D., Koç, A., Erkovan, H.İ., Güllapoğlu, K., Kendir, H., Şahin, N., 2012. Türkiye Bilimsel ve Teknolojik Araştırma Kurumu 106G017 nolu Ulusal Mera Kullanımı ve Yönetim Projesi Sonuç Raporu, Ankara.

Azarnivand, H., Farajollahi, A., Bandak, E., Pouzesh, H., 2011. Assessment of the effects of overgrazing on the soil physical characteristic and vegetation cover changes in rangelands of Hosainabad in Kurdistan province, Iran. Journal of Rangeland Science, (1): 2 95-102.

Babalık, A.A., Fakir, H., 2017. Korunan ve otlatılan mera alanlarında vejetasyon özelliklerinin karşılaştırılması: Kocapınar Merası örneği. Turkish Journal of Forestry, 18(3): 207-211.

Babalık, A.A., Ercan, A., 2018. Eskişehir ili Karaören köyü merasının vejetasyon özelliklerinin belirlenmesi. Turkish Journal of Forestry, 19(3): 246-251.

Çınar, S., Hatipoğlu, R., Avcı, M., İnal, İ., Yücel, C., Avağ, A., 2014. Hatay ili Kırıkhan ilçesi taban meralarının vejetasyon yapısı üzerine bir araştırma. Gaziosmanpaşa Üniversitesi Ziraat Fakültesi Dergisi, 31(2): 52-60.

Dursun, İ., Babalık, A.A., 2018. Isparta ili Çatoluk ormaniçi merasının vejetasyon yapisının belirlenmesi. Turkish Journal of Forestry, 19(3): 233-239.

Gobelle, S.K., Gure, A., 2018. Effects of bush encroachment on plant composition, diversity and carbon stock in Borana rangelands, Southern Ethiopia. International Journal of Biodiversity and Conservation, 10(5): 230-245.

Gökkuş, A., Koç, A., 2001. Mera ve Çayır Yönetimi. Atatürk Üniversitesi Ziraat Fakültesi Ders Notu Yayınları: 228, Erzurum.

Gökkuş, A., Koç, A., Çomaklı, B., 2000. Çayır-Mera Uygulama Kılavuzu. Atatürk Üniversitesi Ziraat Fakültesi, Yayın No: 142, Erzurum. 
Holechek, J.L., Pieper, R.D., Herbel, C. H., 2004. Range Management: Principles and Practices. Prentice Hall, New Jersey.

Karakuş, Y.S., Deveci, M., 2018. Investigating vegetation of mowed and grazed areas in Tamdere village alpine pastures in Turkey. Journal of Rangeland Science, 1(3): 211-226.

Koç, A., Gökkuş, A., Serin, Y., 1994. Türkiye çayır meralarının durumu ve erozyon yönünden önemi. Ekoloji Çevre Dergisi, 13: 36-41.

Koç, A., Gökkuş, A., Altın, M., 2003. Mera durumu tespitinde dünyada yaygın olarak kullanılan yöntemlerin mukayesesi ve Türkiye için bir öneri. Türkiye 5. Tarla Bitkileri Kongresi, 13-17 Ekim, Diyarbakır, s.36-42.
Koç, A., Çakal, Ş., 2004. Comparison of some rangeland canopy coverage methods. International Soil Congress Natural Resource Management for Sustainable Development, 7-10 June, Erzurum, s.41-45.

Seydoşoğlu, S., Kökten, K., Sevilmiş, U., 2018. Basic vegetation characteristics of village pastures connected to Mardin province and its provinces. Turkish Journal of Agricultural and Natural Sciences, 5(4): 406-413.

Uzun, F., Alay, F., İspirli, K., 2016. Bartın ili meralarının bazı özellikleri. Türkiye Tarımsal Araştırmalar Dergisi, (3): 174-183. 